\title{
Geofungos no Córrego do Sapateiro, Parque Municipal do Ibirapuera, São Paulo, SP, Brasil ${ }^{1}$
}

\author{
Juliana Possato Takahashi ${ }^{2,4}$, Iracema Helena Schoenlein-Crusius ${ }^{3}$, Vivian Tafarello Gruppi ${ }^{3}$ e \\ Carolina Gasch Moreira ${ }^{3}$
}

Recebido: 22.09.2011; aceito: 12.06.2012

\begin{abstract}
Geofungi of Córrego do Sapateiro at the Parque Municipal do Ibirapuera, São Paulo, São Paulo State, Brazil). Water samples $(50 \mathrm{~mL})$ at $10 \mathrm{~cm}$ depth were collected from two sites $(1$ and 2), before and after flotation water treatment, during the rainy hot season (January, February, and March) and the dry cold season (June, July, and August) of 2008 in Córrego do Sapateiro at the Parque Municipal do Ibirapuera, São Paulo, São Paulo State Brazil. Temperature, dissolved oxygen, conductivity, and $\mathrm{pH}$ of the water were measured with a $\mathrm{U}_{10}$ Horiba equipment. Total and fecal coliforms were analyzed with an Aquatest ${ }^{\circledR}$ kit. Aliquots of $1 \mathrm{~mL}$ from each water sample were inoculated on potato-dextrose agar medium, totalizing 10 Petri dishes for each collection site. Colonies were quantified after incubation for 10 days at $22{ }^{\circ} \mathrm{C}$ and then purified for identification. Water abiotic parameters did not limit the development of geofungi; however, they were influenced by the flotation treatment. Fecal and total number of coliforms were predominantly higher than $8 \mathrm{NMP}^{\mathrm{dL}}{ }^{-1}$ during the studied periods at the two sites. Twenty-seven fungal taxa, distributed in 136 occurences were obtained. According to Sörensen Similarity Index, the mycobiota of the two simpled sites were considerably different, despite the resemblance between the number of taxa and occurrences. The results indicate that treatment of water from Córrego do Sapateiro flotation system possibly causes changes in taxonomic composition and quantity of fungi CFU, whereas the total and fecal coliform results were less conclusive.
\end{abstract}

Key words: diversity, flotation, geofungi, urban waters

RESUMO - (Geofungos no Córrego do Sapateiro, Parque Municipal do Ibirapuera, São Paulo, SP, Brasil). No Córrego do Sapateiro, situado no Parque Municipal do Ibirapuera, na cidade de São Paulo, SP, Brasil, amostras de água (50 mL) na profundidade de 10 centímetros foram coletadas em locais antes (local 1) e depois (local 2) da estação de tratamento de flotação, durante os meses da estação chuvosa e quente (janeiro, fevereiro e março) e da estação seca e fria (junho, julho e agosto) de 2008. Além disso, a temperatura, oxigênio dissolvido, condutividade e $\mathrm{pH}$ da água foram medidos com um equipamento Horiba $\mathrm{U}_{10}$. Coliformes totais e fecais foram analisados com o kit Aquatest $\mathbb{R}$. A partir de cada amostra de água, alíquotas de $1 \mathrm{~mL}$ foram inoculadas em meio batata-dextrose-ágar, totalizando 10 placas de Petri para cada local de coleta. Após incubação por 10 dias a $22^{\circ} \mathrm{C}$, as colônias fúngicas foram quantificadas, purificadas e identificadas. Os parâmetros abióticos da água não foram limitantes para a presença de geofungos, sendo influenciados pelo tratamento de flotação. Nos dois locais o número de coliformes totais e fecais foi predominantemente superior a $8 \mathrm{NMP} \mathrm{dL}^{-1}$ durante o período estudado. Vinte e sete táxons de fungos foram obtidos, distribuídos em 136 ocorrências. De acordo com o índice de similaridade de Sörensen, a micota dos dois locais coletados foram consideravelmente diferentes, apesar da semelhança entre o número de táxons e ocorrências. Os resultados indicam que o tratamento da água do Córrego do Sapateiro pelo sistema de flotação possivelmente causa modificações na composição taxonômica e na quantidade de UFC de fungos, ao contrário do que ocorreu com os coliformes totais e fecais, cujos resultados apresentaram-se menos conclusivos.

Palavras-chave: águas urbanas, diversidade, flotação, geofungos

\section{Introdução}

O Córrego do Sapateiro constitui um dos principais fornecedores de água para os lagos que compõem a paisagem do Parque Municipal do Ibirapuera, localizado na zona sul da cidade de São Paulo (Prefeitura do Município de São Paulo 2005). A sua maior parte está canalizada, sendo que durante décadas

1. Parte da Dissertação de Mestrado da primeira Autora

2. Universidade Estadual Paulista, Departamento de Bioquímica e Microbiologia, Av. 24A, 1515, 13506-900 Rio Claro, SP, Brasil

3. Instituto de Botânica, Núcleo de Pesquisas em Micologia, Caixa Postal 68041, 04045-972 São Paulo, SP, Brasil

4. Autor para correspondência: jusavoia@yahoo.com.br 
recebeu grande aporte de águas pluviais dos bairros que circundam o Parque, acarretando má qualidade de suas águas, tanto sob o ponto de vista de fatores abióticos (teor de oxigênio dissolvido, $\mathrm{pH}$ e grau de eutrofização), como microbiológicos (coliformes fecais e totais), oferecendo riscos principalmente para as aves que ali vivem (Oliveira et al. 2001, Prefeitura do Município de São Paulo 2005). Diante dessa situação, tornou-se imprescindível tratar a água do referido córrego, antes da entrada das mesmas nos lagos. Optou-se pela flotação, na qual uma expressiva parte da matéria orgânica em suspensão é retirada da água através de floculação e micro-oxigenação, resultando em maior transparência da mesma, permitindo a obtenção de água no padrão adequado para uso paisagístico (Oliveira et al. 2001).

A CETESB (Companhia de Tecnologia de Saneamento Ambiental) realiza monitoramento das qualidades químicas e físicas dessas águas para acompanhar a eficiência do processo de flotação. Há informações de que o processo reduz significativamente o número de coliformes totais e fecais (Oliveira et al. 2001). Porém ainda não se conhece a composição de micota no Córrego do Sapateiro antes e depois da estação de tratamento.

Os geofungos podem desenvolver-se em qualquer substrato e muitas vezes em qualquer ambiente, embora algumas espécies sejam restritas a ambientes e substratos específicos (Alexopoulos 1996).

Cooke (1976) verificou alteração na composição da micota nos ambientes aquáticos poluídos, havendo dominância de espécies de geofungos, principalmente pertencentes ao grupo dos fungos anamórficos, justificando a escolha desse grupo de fungos para o presente estudo.

No Brasil são escassos os trabalhos sobre o assunto, estando publicados os de Martins et al. (1989) e Ceballos et al. (1995).

\section{Material e métodos}

O levantamento dos geofungos foi realizado no Parque Municipal do Ibirapuera, localizado no bairro de Vila Mariana na cidade de São Paulo, na unidade de flotação mantida pela SABESP. Para a coleta de amostras de água foram escolhidos dois locais no Córrego do Sapateiro, localizados na entrada e saída da unidade de flotação, respectivamente. A localização geográfica dos locais de coleta foi estabelecida com aparelho GPS Garmin. O local 1, antes da estação de flotação, localiza-se a 2335'405"S e 46039'198"W e o local 2, após o tratamento, localiza-se a $23^{\circ} 35^{\prime} 325^{\prime \prime S}$ e 463' $485^{\prime \prime} \mathrm{W}$.

Em cada local, foram coletadas duas amostras de água $(50 \mathrm{~mL})$ a profundidade aproximada de $10 \mathrm{~cm}$ a partir da superfície e a distância de $10 \mathrm{~cm}$ da margem, em três meses na época chuvosa (janeiro/ fevereiro/março) e três meses na época seca (junho/ julho/agosto), em 2008. Foram utilizados coletores de plástico universais para a coleta das amostras de água, que foram transportadas rapidamente para o laboratório e processadas no mesmo dia.

Concomitantemente às coletas de água foram determinados, a $20 \mathrm{~cm}$ de profundidade, nos locais de coleta, os parâmetros físicos: temperatura, oxigênio dissolvido, condutividade e $\mathrm{pH}$, com o auxílio de equipamento $U_{10}$ da Horiba. As amostras de água coletadas para essa finalidade foram submetidas ao teste para coliformes totais e fecais da Aquatest ${ }^{\circledR}$ (Laborclin - Brasil), que se baseia na quantificação por NMP (número mais provável de unidades formadoras de colônias por decilitro de amostra), sendo que o mínimo a ser detectado é menor que $1,1 \mathrm{NMPdL}^{-1} \mathrm{e}$ o máximo é maior que $8 \mathrm{NMPdL}^{-1}$. Após esse período e constatada a positividade para coliformes totais nos tubos, foi feita a prova confirmatória com tubos de Aquatest para avaliar a presença de coliformes fecais, seguindo as normas técnicas da American Public Health Association (1998).

Para o isolamento dos fungos cada amostra de água coletada foram retiradas alíquotas de $1 \mathrm{~mL}$, e espalhada com auxílio de uma espátula de Drigalsky, sobre a superfície do meio de cultura batata-dextrose-ágar (BDA) sem antibiótico, contido em placas-de-Petri. O plaqueamento direto das alíquotas é uma adaptação análoga à técnica tradicional da placa de solo de Warcup (1950). Foram utilizadas 10 placas-de-Petri para semeadura da água do Córrego do Sapateiro antes da flotação (local 1) e 10 para a semeadura da água coletada após o tratamento (local 2). Após a incubação das placas durante 10 dias a $22^{\circ} \mathrm{C}$, as colônias foram quantificadas por contagem visual. As colônias mais representativas foram transferidas para o meio BDA para serem purificadas e posteriormente identificadas.

A identificação dos geofungos baseou-se nas características morfológicas dos fungos crescidos em culturas, de acordo com chaves taxonômicas (Barron 1968, Booth 1971, Ellis 1971, Domsch et al. 1993, Barnett \& Hunter 1998, Pitt 2000, Leslie \& Summerell 2006). Os fungos isolados das amostras de águas foram incorporados na Coleção de Culturas do Instituto de Botânica (CCIBt). 
Para o tratamento estatístico dos resultados foi utilizada a fórmula de frequência de ocorrência das espécies (Zag \& Willing 2004), o índice de similaridade de Sörensen (Mueller-Dumbois \& Ellenberg 1974) e o teste $t$ de Student em par para médias, considerando $p<0,05$.

\section{Resultados e Discussão}

Nos locais de coleta 1 e 2 a temperatura atingiu mínima de $19{ }^{\circ} \mathrm{C}$ em junho e máxima de $24{ }^{\circ} \mathrm{C}$ em fevereiro de 2008, como pode ser observado na tabela 1, não havendo diferença estatisticamente significativa entre os dois locais $(p<0,05)$.

As atividades vitais dos fungos como germinação e esporulação são afetadas diretamente pela temperatura, sendo os geofungos muito bem adaptados às variações ambientais (Park 1968, Sparrow 1968). Dix \& Webster (1995) demonstraram que em diversas espécies fúngicas o crescimento é estimulado sob pequenos aumentos de temperatura, podendo ocorrer o contrário na diminuição da mesma. Os valores desta variável registrados no presente estudo encontram-se dentro dos comumente citados na literatura para águas doces (Tundisi \& Tundisi 2008).

$\mathrm{O}$ pH é definido como o logaritmo negativo da concentração hidrogeniônica. Ele pode ser considerado uma variável de grande importância em qualquer ambiente pela interdependência entre as comunidades vegetais e o meio aquático, sendo que as comunidades aquáticas interferem no $\mathrm{pH}$, assim como o $\mathrm{pH}$ interfere de diferentes maneiras no metabolismo das comunidades no ecossistema (Esteves 1998).

Os valores de $\mathrm{pH}$ nos locais da coleta em 2008 foram, respectivamente: local 1 (mínimo de 4,9 e máximo de 7,4 em junho e março); local 2 (mínimo de 4,8 e máximo de 7,4 em junho e março), demonstrando uma leve variação entre os dois locais, apesar de não haver diferença estatisticamente significativa $(p<0,05)$.

A Resolução do Conselho Nacional do Meio Ambiente, $n^{\circ} 357$ (CONAMA 2005), dispõe sobre a classificação dos corpos de água e diretrizes ambientais para o seu enquadramento e estabelece as condições e padrões para o lançamento de efluentes. Para águas doces, denomina como classe 4 a utilização das águas para harmonia paisagística e para navegação.

Os valores pré-estabelecidos pelo CONAMA (CONAMA 2005) para pH em águas doces estão entre 6 e 9, sendo assim, o mês de junho é o único que não se enquadra nessa classificação.

Tundisi \& Tundisi (2008) apontaram que a poluição atmosférica é um componente fundamental que influencia a composição química da água da chuva, contribuindo com vários íons como $\mathrm{HSO}_{4}^{-} \mathrm{e}$ óxidos de nitrogênio. Assim, como consequência, o $\mathrm{pH}$ da água da chuva pode atingir valores abaixo de 4,0 chegando a 2,1. Esses autores demonstraram também que as modificações ambientais produzidas pelas atividades humanas podem contribuir para a alteração na composição química das águas naturais como, por exemplo, na remoção da cobertura vegetal,

Tabela 1. Valores individuais das variáveis abióticas determinadas de janeiro a agosto de 2008 nos locais 1 (antes do tratamento) e 2 (depois do tratamento) da Estação de Tratamento e Remoção de Efluentes da SABESP, localizada no Parque Municipal do Ibirapuera, São Paulo, SP, Brasil.

Table 1. Individual values of abiotic variables determined from January to August 2008 at sites 1 (before treatment) and 2 (after treatment), SABESP's Wastewater Treatment and Removal Plant, located at Parque Municipal do Ibirapuera, São Paulo, São Paulo State, Brazil.

\begin{tabular}{|c|c|c|c|c|c|c|c|c|}
\hline Locais & Janeiro & Fevereiro & Março & Junho & Julho & Agosto & Média & Desvio padrão \\
\hline \multicolumn{9}{|l|}{ Local 1} \\
\hline Temperatura $\left({ }^{\circ} \mathrm{C}\right)$ & 23,00 & 24,00 & 23,00 & 19,00 & 20,40 & 21,50 & 21,80 & 1,87 \\
\hline $\mathrm{pH}$ & 7,20 & 7,10 & 7,40 & 4,90 & 7,10 & 6,50 & 6,70 & 0,93 \\
\hline Condutividade $\left(\mathrm{mS} \mathrm{cm}^{-1}\right)$ & 0,25 & 0,31 & 0,24 & 0,24 & 0,29 & 0,25 & 0,26 & 0,03 \\
\hline $\mathrm{O}_{2}$ dissolvido (mg L-1) & 4,90 & 3,10 & 4,10 & 3,50 & 2,30 & 5,00 & 3,81 & 1,05 \\
\hline Local 2 & Janeiro & Fevereiro & Março & Junho & Julho & Agosto & Média & Desvio padrão \\
\hline Temperatura $\left({ }^{\circ} \mathrm{C}\right)$ & 23,00 & 24,00 & 23,00 & 19,00 & 20,00 & 21,30 & 21,70 & 1,94 \\
\hline $\mathrm{pH}$ & 7,20 & 7,10 & 7,40 & 4,80 & 6,70 & 6,00 & 6,50 & 0,98 \\
\hline Condutividade $\left(\mathrm{mS} \mathrm{cm}^{-1}\right)$ & 0,25 & 0,30 & 0,23 & 0,23 & 0,16 & 0,27 & 0,24 & 0,04 \\
\hline $\mathrm{O}_{2}$ dissolvido $\left(\mathrm{mg} \mathrm{L}^{-1}\right)$ & 8,50 & 6,70 & 7,40 & 8,20 & 6,40 & 5,30 & 7,08 & 1,19 \\
\hline
\end{tabular}


tratamentos diversos do solo e despejos industriais ou agrícolas. Portanto, o pH baixo no mês de junho pode indicar que nesse período seco houve um maior despejo de efluentes domésticos ou maior concentração desses diminuindo o $\mathrm{pH}$ das águas.

Em relação à condutividade, no local $1 \mathrm{o}$ valor mínimo foi de $0,24 \mathrm{mS} \mathrm{cm}{ }^{-1}$ em março e junho, enquanto o máximo foi de $0,31 \mathrm{mS} \mathrm{cm}^{-1} \mathrm{em}$ fevereiro. No local 2 o valor mínimo foi de $0,16 \mathrm{mS} \mathrm{cm}^{-1}$ em julho e o máximo foi de $0,30 \mathrm{mS} \mathrm{cm}^{-1} \mathrm{em}$ fevereiro de 2008 (tabela 1), não havendo diferença estatisticamente significativa $(p<0,05)$ em ambos os locais. A condutividade é a capacidade da água de conduzir corrente elétrica, sendo diretamente dependente das concentrações iônicas, do $\mathrm{pH}$ e da temperatura (Tundisi \& Tundisi 2008).

A condutividade elétrica da água constitui uma das variáveis abióticas de grande relevância por indicar importantes informações sobre o metabolismo do ecossistema aquático, tal como a magnitude da concentração iônica, composta principalmente pelos macronutrientes como cálcio, magnésio, potássio, sódio e os carbonatos. Além disso, as variações da condutividade podem auxiliar na detecção de fontes poluidoras nos ecossistemas aquáticos (Esteves 1998). No presente estudo não houve influência da condutividade com os fatores bióticos.

O teor de oxigênio dissolvido medido no local 1 apresentou o valor mínimo de $2,3 \mathrm{mg} \mathrm{L}^{-1} \mathrm{em}$ julho e o valor máximo de 5,0 $\mathrm{mg} \mathrm{L}^{-1}$ em agosto de 2008. Já o local 2 apresentou o valor mínimo de $5,3 \mathrm{mg} \mathrm{L}^{-1}$ em agosto e valor máximo de $8,5 \mathrm{mg} \mathrm{L}^{-1} \mathrm{em}$ janeiro de 2008, demonstrando diferença estatisticamente significativa $(p<0,05)$, de acordo com a tabela 1 .

O oxigênio dissolvido apresenta grandes variações diárias por estar diretamente envolvido com os processos de fotossíntese, respiração e/ou decomposição, bem como com o fotoperíodo, a intensidade luminosa e a temperatura (Esteves 1998, Tundisi \& Tundisi 2008).

O aumento do oxigênio dissolvido na água pode ser ocasionado por processos de transporte vertical por efeito da turbulência, como resultado da ação do vento, sendo que esse fluxo turbulento promove a oxigenação das camadas superiores. Já a diminuição do oxigênio dissolvido no ambiente aquático pode ser acarretada pela respiração de plantas e animais aquáticos e a atividade bacteriana de decomposição. A alta concentração de material em suspensão na água, após intensas precipitações e drenagem para lagoas, represas ou rios, também pode diminuir drasticamente o oxigênio. No caso da interface sedimento-água, podem ocorrer perdas substanciais de oxigênio da água, em razão da atividade bacteriana e da oxidação química (Tundisi \& Tundisi 2008).

O local 1 apresentou baixos valores de oxigênio enquanto no local 2 os teores geralmente corresponderam ao dobro em relação ao primeiro. Supõe-se então, que o processo de flotação pode ter contribuído para este resultado, já que o processo inclui uma fase de aeração.

Tundisi \& Tundisi (2008) descreveram que os organismos aquáticos têm dependência fundamental em relação à concentração e saturação de oxigênio na água, sendo que a distribuição vertical e horizontal de oxigênio dissolvido na água produz alterações na distribuição dos organismos e seu comportamento.

Nas coletas de água realizadas no local 1 e 2, o número de coliformes totais e fecais foi maior que $8 \mathrm{NMP} \mathrm{dL}^{-1}$, nos meses de junho, outubro e novembro de 2008 e janeiro e fevereiro de 2009.

Os coliformes têm sido úteis para medir a ocorrência e grau de poluição fecal em águas há aproximadamente 70 anos (Souza et al. 1983). Vários autores questionam seu papel, pois nem sempre são isolados e por efeitos ambientais podem multiplicar-se em águas não necessariamente poluídas com fezes (Ceballos et al. 1995). Os coliformes fecais têm sido os indicadores de poluição mais frequentemente utilizados na avaliação da qualidade da água (Martins et al. 1989).

Segundo Kay \& McDonald (1980), os principais fatores que influenciam o decaimento bacteriano num corpo d'água são temperatura, sedimentação, níveis de nutrientes, pH, luz solar, floculação, adsorção, predadores, filtração e oxigênio dissolvido.

Oliveira et al. (2001) citaram que a introdução de polímeros fortemente aniônicos ou catiônicos, após a reação de floculação com as poliacrilamidas de alto peso molecular em emulsão, garante alta taxa de redução nas concentrações de coliformes totais e fecais, pois, promovem uma filtração química na massa de água em tratamento.

ASABESP juntamente com a CETESB realizaram ensaios analíticos referentes a alguns parâmetros de qualidade nas águas do Córrego do Sapateiro, após a implantação da Estação de Flotação e Remoção de Flutuantes, no ano de 2000. A eficiência de remoção foi calculada com base nos resultados obtidos para as respectivas amostras afluentes (pré-tratamento) e efluentes (pós-tratamento) entre janeiro e setembro de 2001. Esses dados mostram que a remoção de 
coliformes fecais foi de $99,4 \%$ (Oliveira et al. 2001). Entretanto, no presente estudo observou-se que os valores dos coliformes totais e fecais mantiveram-se semelhantes nos dois pontos de coleta, com leves variações nos meses de julho e agosto de 2008 .

Oliveira et al. (2001) relataram a existência desde 1998, de um excesso de matéria orgânica proveniente de esgotos domésticos descarregados no Córrego do Sapateiro, principalmente por ligações clandestinas em drenagens pluviais .

No local 1, nos meses de janeiro, março e agosto de 2008, o número de colônias variou com a mínima de

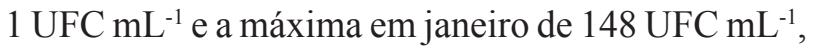
por outro lado, no local $2 \mathrm{em}$ fevereiro, março, junho, julho e agosto de 2008, o número mínimo de colônias foi de zero UFC $\mathrm{mL}^{-1}$ e o máximo em janeiro de $54 \mathrm{UFC} \mathrm{mL}^{-1}$ (tabela 2).

Martins et al. (1989) demonstraram no Córrego do Agrião afluente do rio Jacaré-Pepira, São Paulo, SP, na primeira e segunda estiagens, valores elevados de UFC $\mathrm{mL}^{-1} \mathrm{em}$ alguns pontos, sendo que essa elevação pode ter sido devida ao aumento no despejo de esgoto, acrescentando matéria orgânica favorável ao crescimento de fungos filamentosos. Já no período de chuvas o número de $\mathrm{UFC} \mathrm{mL}^{-1}$ manteve-se homogêneo praticamente por todo o córrego, provavelmente pelo aumento do fluxo de água corrente, distribuindo esporos por todo o córrego.
No Canadá, no córrego Ontário, Qureshi \& Dutka (1974), obtiveram grande número de UFC $\mathrm{mL}^{-1}$ nas margens em relação à parte central do córrego, o que provavelmente se deve à contribuição do aumento da matéria orgânica proveniente do solo e dos despejos das margens para dentro do córrego.

O presente estudo demonstra similaridades com os descritos anteriormente, apontando que o lançamento de esgoto acarreta o aumento da matéria orgânica na água, o que resulta em um aumento no crescimento dos fungos filamentosos. Contudo, neste estudo observou-se maior quantidade de fungos filamentosos na época chuvosa, ao contrário de outros artigos que citam a diminuição do número de colônias nessa época (Qureshi \& Dukta 1974, Maki et al. 1984). Pode-se supor que o aumento da dispersão dos fungos no Córrego do Sapateiro na época das chuvas esteja relacionado com o aumento de volume de água. As chuvas poderiam carrear para dentro do córrego grande quantidade de detritos e solo o que justificaria a maior quantidade de colônias de fungos na água. $\mathrm{Na}$ época seca a quantidade de fungos nas águas do córrego tende a diminuir, devido a pouca disponibilidade de nutrientes. No caso do sistema de flotação, pode-se supor que a diminuição da UFC dos fungos após esse processo é devido à retirada da matéria orgânica particulada da água pela floculação, o que diminui a disponibilidade de nutrientes para

Tabela 2. Contagem de unidades formadoras de colônias de fungos por UFC mL $\mathrm{mL}^{-1} \mathrm{em}$ BDA das amostras de água dos locais 1 (antes do tratamento) e 2 (após o tratamento) da Estação de Tratamento e Remoção de Efluentes da SABESP, localizada no Parque Municipal do Ibirapuera em São Paulo, SP, Brasil, de janeiro a agosto de 2008.

Table 2. Counting of fungal colony-forming units by CFU per mL of BDA in water samples from sites 1 (before treatment) and 2 (after treatment), SABESP's Wastewater Treatment and Removal Plant, located at Parque Municipal do Ibirapuera em São Paulo, São Paulo, São Paulo State, Brazil, from January to August 2008.

\begin{tabular}{|c|c|c|c|c|c|c|}
\hline \multirow[t]{2}{*}{ Locais } & \multicolumn{3}{|c|}{ Época chuvosa } & \multicolumn{3}{|c|}{ Época Seca } \\
\hline & Janeiro & Fevereiro & Março & Junho & Julho & Agosto \\
\hline \multicolumn{7}{|l|}{ Local 1} \\
\hline $\begin{array}{l}\text { Contagem de colônias } \\
\text { por placa UFC } \mathrm{mL}^{-1}\end{array}$ & $\begin{array}{l}30,89,90 \\
148\end{array}$ & $\begin{array}{l}2,3,4,5,9,10 \\
14,17,21,28\end{array}$ & $\begin{array}{l}1,9,20,21,22, \\
28,32,33,35,46\end{array}$ & $\begin{array}{l}4,5,5,6,6 \\
7,8,9,10,14\end{array}$ & $\begin{array}{l}17,22,26,29,32 \\
32,33,34,34,43\end{array}$ & $\begin{array}{l}1,1,1,2,2 \\
4,4,5,5,8\end{array}$ \\
\hline Médias & 89,25 & 11,30 & 24,70 & 7,40 & 30,20 & 3,30 \\
\hline Desvio Padrão & 48,17 & 8,62 & 13,10 & 2,98 & 7,21 & 2,31 \\
\hline \multicolumn{7}{|l|}{ Local 2} \\
\hline $\begin{array}{l}\text { Contagem de colônias } \\
\text { por placa UFC } \mathrm{mL}^{-1}\end{array}$ & $11,21,23,54$ & $\begin{array}{l}0,1,1,2,2 \\
2,3,4,5,20\end{array}$ & $\begin{array}{l}0,0,0,2,3,3 \\
4,7,10,14\end{array}$ & $\begin{array}{l}0,1,1,2,2 \\
2,2,2,3,7\end{array}$ & $\begin{array}{l}0,1,1,1,1 \\
2,2,2,3,26\end{array}$ & $\begin{array}{l}0,2,2,3,3, \\
3,5,6,7,40\end{array}$ \\
\hline Médias & 27,25 & 4,00 & 4,40 & 2,20 & 3,90 & 3,30 \\
\hline Desvio Padrão & 18,60 & 5,81 & 4,67 & 1,87 & 7,80 & 2,31 \\
\hline
\end{tabular}


os microrganismos, acarretando numa pequena quantidade de colônias de fungos. Outra hipótese é que o sistema de flotação retire as partículas juntamente com os conídios, diminuindo assim a contagem de UFC. Para comprovar essas hipóteses são necessários estudos específicos sobre o comportamento das UFC durante cada etapa do processo de flotação.

A ocorrência dos fungos nas águas do Córrego do Sapateiro foi dividida em época chuvosa e quente, que abrange os meses de janeiro a março e em época seca e fria, no período de junho a agosto de 2008. Considerando as duas épocas em conjunto foram obtidos 27 táxons de fungos, distribuídos em 136 ocorrências. Somando as ocorrências dos fungos, verificou-se que na época chuvosa e quente foram registradas 74 ocorrências, já na época seca e fria, 67. Quanto ao número de táxons, na época chuvosa e quente foram verificados 20 , e na outra época foram contabilizados 21 táxons de fungos (tabela 3 ).

Esses resultados não indicam comportamento sazonal característico dos fungos, sendo que somente pode-se supor que há tendência e menor diversidade e ocorrência de fungos nas épocas mais frias e secas, como no mês de agosto de 2008, que se caracterizou pelos menores números de táxons e de ocorrências no período de estudo. No entanto, a maior ocorrência dos fungos em junho de 2008 dificulta a interpretação conclusiva desses resultados. Na literatura são mencionadas maiores incidências de fungos na água tanto na época chuvosa e quente (Ceballos et al. 1995), quanto nas épocas frias e secas (Martins et al. 1989), ou a ausência de comportamento sazonal, tal como foi observado por Schoenlein-Crusius (1993) em riacho situado na Mata Atlântica de Paranapiacaba. Analisando a presença dos fungos com relação aos dois locais de coleta, verificou-se que no local 1 foram obtidos 24 táxons e no local 2, 20. O número máximo de ocorrências de fungos correspondeu a 76 , no local 1 , enquanto que no local 2 esse número correspondeu a 65. Dessa forma, pode-se verificar que tanto a diversidade quanto o número de ocorrências de fungos apresentaram-se maior no local antes do tratamento da água pelo processo de flotação. No entanto de acordo com o teste $t$ de Student essas diferenças não foram estatisticamente significativas $(p<0,05)$.

A micota observada no Córrego do Sapateiro, no período amostral, constituiu-se de nove gêneros de fungos anamórficos, sendo eles Aspergillus, Cladosporium Cylindrocladium, Fusarium, Geotrichum, Paecilomyces, Penicillium,
Pestalotiopsis, Trichoderma, e fungos não esporulantes aqui denominados FNE.

Nove táxons ocorreram exclusivamente no local 1 (Aspergillus japonicus, Cylindrocladium scoparium, Cladosporium sphaerospermum, Fusarium heterosporum, Geotrichum candidum, Penicillium decumbens, P. sclerotiorum, Pestalotiopsis sp. e Trichoderma koningi) e quatro táxons no local 2 (Paecilomyces sp., Penicillium corylophilum, $P$. islandicum e $P$. restrictum).

Os gêneros encontrados são frequentemente citados como cosmopolitas e de típica origem terrestre, estando presentes tanto em ambientes preservados como nos impactados (Domsch et al. 1993). No Estado do Missouri nos Estados Unidos, Noell (1973) obteve 689 registros de fungos, perfazendo o total de 20 táxons divididos em 14 gêneros dentre os quais Fusarium, Verticillium, Acremonium, Aspergillus e Pestalotia, de rochas de córregos poluídos por efluentes de esgotos. O autor chama a atenção ao fato de que os fungos foram recuperados em maior quantidade nas margens do que no centro do córrego, possivelmente porque a correnteza tende a depositar partículas, incluindo propágulos junto às margens. No centro do córrego, os fungos estão sujeitos aos mecanismos de rompimento e carreamento como a velocidade da correnteza, arrastando pedras e detritos córrego abaixo, assim justificando a menor quantidade de isolados desse local. Também Qureshi \& Dutka (1974) isolaram representantes dos gêneros Aspergillus, Fusarium, Penicillium, Cladosporium e Trichoderma, com grande frequência no córrego Ontário.

A composição da micota encontrada no Córrego do Sapateiro, também é semelhante à encontrada por Martins et al. (1989). Naquele estudo foram obtidos 25 táxons na seguinte ordem de frequência: fungos não esporulados (FNE), Fusarium sp., Cladosporium sp., Trichoderma sp., Penicillium sp., Phoma sp., Aspergillus sp., Cephalosporium sp., Mucor sp. e Geotrichum sp., reforçando o aspecto ubíquo dos mesmos.

Ceballos et al. (1995) estudaram a ocorrência de fungos filamentosos nos lagos Boqueirão, Bodocongó e Açude Velho no Estado da Paraíba, obtendo 24 táxons, incluindo Penicillium sp., FNE, Curvularia sp., Cladosporium sp., Rhizopus sp. e Aspergillus sp. O isolamento de elevada quantidade de fungos não esporulantes coincidiu com os elevados níveis de coliformes fecais, indicando possível associação entre a diversidade da micota e coliformes. 
Tabela 3. Total de ocorrências dos táxons dos fungos isolados das amostras de água do local 1 (antes do tratamento) e do local 2 (após o tratamento) na Estação de Tratamento e Remoção de Efluentes da SABESP, localizada no Parque Municipal do Ibirapuera, São Paulo, SP, Brasil, de janeiro a agosto de 2008.

Table 3. Total occurrences of fungi taxa isolated from water samples at site 1 (before treatment) and site 2 (after treatment), SABESP's Wastewater Treatment and Removal Plant, located at Parque Municipal do Ibirapuera, São Paulo, São Paulo State, Brazil, from January to August 2008.

\begin{tabular}{|c|c|c|c|c|c|c|c|c|c|c|c|c|c|}
\hline Fungos identificados & & & Epoca & chuve & & & & & Épor & ca se & & & \\
\hline & & & & & & & & & & & & & $\begin{array}{l}\text { Número total } \\
\text { de ocorrências }\end{array}$ \\
\hline & Jane & & $\mathrm{Fev}$ & reiro & $\mathrm{Ma}$ & & Junh & & Julhc & & $\mathrm{Ag}$ & & \\
\hline Loca1s & 1 & 2 & 1 & 2 & 1 & 2 & 1 & 2 & 1 & 2 & 1 & 2 & \\
\hline Aspergillus japonicus Saito & - & - & - & - & 1 & - & - & - & - & - & - & - & 1 \\
\hline $\begin{array}{l}\text { Cladosporium cladosporioides } \\
\text { (Fresen.) G.A. de Vries }\end{array}$ & 1 & 1 & - & - & 1 & - & 3 & 4 & - & - & - & 1 & 11 \\
\hline C. sphaerospermum Penz. & - & - & - & - & - & - & 1 & - & - & - & - & - & 1 \\
\hline Cylindrocladium scoparium Morgan & - & - & - & - & - & - & - & - & 2 & - & - & - & 2 \\
\hline $\begin{array}{l}\text { Fusarium heterosporum Nees \& T. } \\
\text { Nees }\end{array}$ & - & - & - & - & - & - & 1 & - & - & - & - & - & 1 \\
\hline F. moniliforme J. Sheld. & 2 & - & - & 1 & 1 & 1 & 3 & 2 & 1 & - & - & 2 & 13 \\
\hline F. oxysporum Schlecht. & 2 & 1 & 2 & - & 2 & - & - & 2 & 1 & - & - & - & 10 \\
\hline F. solani (Mart.) Sacc. & 1 & - & 2 & 2 & 1 & - & - & - & - & - & - & - & 6 \\
\hline Geotrichum candidum Link & - & - & - & - & - & - & 1 & - & 1 & - & - & - & 2 \\
\hline Paecilomyces sp. & - & - & - & - & - & - & - & - & - & - & - & 1 & 1 \\
\hline Penicillium corylophilum Dierckx & - & - & - & 1 & - & - & 1 & - & - & - & - & 1 & 3 \\
\hline P. decumbens Thom & 1 & - & - & - & - & - & - & - & - & - & - & - & 1 \\
\hline P. islandicum Sopp & - & - & - & - & - & - & - & 1 & - & - & - & - & 1 \\
\hline $\begin{array}{l}\text { P. restrictum J.C. Gilman \& E.V. } \\
\text { Abbott }\end{array}$ & - & - & - & - & - & - & - & - & - & 1 & - & - & 1 \\
\hline P. rugulosum Thom & - & - & 4 & 3 & 3 & 1 & - & 2 & - & 2 & - & - & 15 \\
\hline P. sclerotiorum J.F.H. Beyma & - & - & 1 & - & - & - & - & - & - & - & - & - & 1 \\
\hline P. waksmanii K.M. Zalessky & - & - & - & 1 & - & - & 1 & - & 1 & 2 & - & - & 5 \\
\hline Pestalotiopsis sp. & - & - & 1 & - & - & - & - & - & - & - & - & - & 1 \\
\hline Trichoderma aureoviride Rifai & 1 & 1 & - & - & - & 1 & - & - & 2 & - & - & - & 5 \\
\hline T. citrinoviride Bissett & - & - & - & 1 & 1 & 1 & - & - & - & - & - & - & 3 \\
\hline $\begin{array}{l}\text { T. ghanense Yoshim. Dói, Y. Abe \& } \\
\text { Sugiy. }\end{array}$ & 1 & - & 2 & - & - & 2 & - & - & - & - & - & - & 5 \\
\hline T. koningi Oudem. & - & - & - & - & 1 & - & - & - & - & - & - & - & 1 \\
\hline T. longibrachiatum Rifai & - & - & 1 & - & - & - & - & - & - & 1 & - & - & 2 \\
\hline T. pseudokoningii Rifai & 1 & 3 & 2 & - & - & 2 & 2 & - & 4 & - & 1 & - & 15 \\
\hline $\begin{array}{l}\text { T. virens (J.H. Mill., Giddens \& A.A. } \\
\text { Foster) Arx }\end{array}$ & 1 & 2 & 1 & 1 & - & - & - & - & 1 & - & 1 & - & 7 \\
\hline T. viride Pers. & 1 & 1 & 1 & 1 & - & 2 & - & - & - & - & - & - & 6 \\
\hline Fungos não esporulantes & 2 & - & - & 1 & - & 1 & 2 & 3 & 3 & - & - & 4 & 16 \\
\hline Total de táxons & 11 & 6 & 10 & 9 & 8 & 8 & 9 & 6 & 9 & 4 & 2 & 5 & 136 \\
\hline Total de ocorrências mensais por local & 14 & 9 & 17 & 12 & 11 & 11 & 15 & 14 & 16 & 6 & 2 & 9 & \\
\hline Total de táxons por mês & 17 & & 19 & & 16 & & 16 & & 14 & & 7 & & \\
\hline Total de ocorrências por mês & 23 & & 29 & & 22 & & 30 & & 23 & & 11 & & \\
\hline
\end{tabular}


Resultados semelhantes também foram reportados por Cavalcanti (2001) no estudo dos fungos terrestres isolados dos Açudes do Prata e do Meio, em Recife, PE, no qual também predominaram gêneros cosmopolitas tais como Acremonium, Cladosporium, Paecilomyces, Pestalotiopsis, Penicillium e Trichoderma.

A grande diversidade de espécies de fungos considerados terrestres na água pode caracterizar esse ambiente como eficiente reservatório de propágulos para a ciclagem de matéria orgânica alóctone no riacho, comprovando a importância desses fungos nos ecossistemas aquáticos, como mencionado por Park (1972). O fato de a micota estar composta por espécies cosmopolitas e resistentes a condições adversas como poluição e eutrofização das águas pode indicar certa capacidade de autodepuração do sistema, o que é importante para a sua recuperação e conservação.

O índice de similaridade de Sörensen foi aplicado para comparar a semelhança da micota aquática entre os dois locais estudados confrontando os locais 1 e 2 em cada coleta. Assim, a similaridade entre a micota dos locais 1 e 2 correspondeu a 55\% na primeira coleta (janeiro/2008), 29\% na segunda (fevereiro/2008), 27\% na terceira (março/2008), 19\% na quarta (junho/2008), $8 \%$ na quinta (julho/2008) e zero na sexta coleta (agosto/2008).

$\mathrm{O}$ número total de táxons de fungos manteve-se em torno de 16 e o número total de ocorrências em torno de 23 ao longo dos meses, com exceção de agosto, quando caiu para sete táxons e 11 ocorrências. Depreende-se disso que a composição da micota nos dois locais tornou-se gradativamente diferente com o passar dos meses, independentemente do número de táxons ou de ocorrências. Como a similaridade abaixo de 50\%, de acordo com Christensen (1989), pode ser considerada baixa, os índices encontrados no presente estudo indicam que a composição da micota no local 1 , antes da flotação, diferiu consideravelmente daquela observada no local 2, após a flotação. Os parâmetros abióticos determinados na água do Córrego do Sapateiro não se apresentaram limitantes para a presença de geofungos e foram pouco influenciados pelo tratamento da água, com exceção do oxigênio dissolvido, que no local após a flotação apresentou teores significativamente mais elevados.

Os resultados indicam que o tratamento da água do Córrego do Sapateiro pelo sistema de flotação possivelmente causa modificações na composição taxonômica e na quantidade de UFC de fungos, ao contrário do que ocorre com os coliformes totais e fecais, cujos resultados apresentaram-se menos conclusivos.

\section{Agradecimentos}

Os autores agradecem à CAPES pela bolsa de mestrado concedida à primeira autora e à Administração da SABESP, unidade de flotação do Parque Municipal do Ibirapuera pela permissão para coletar as amostras na estação de tratamento.

\section{Literatura citada}

Alexopoulos, C.J., Mims, C.W. \& Blackwell, M.1996. Introductory Mycology. 4 ed. New York, John Wiley \& Sons.

American Public Health Association. 1998. Standard methods for the examination of water and wastewater: American Public Health Association (APHA), the American Water Works Association (AWWA), and the Water Environment Federation (WEF), Washington.

Barnett, H.L. \& Hunter, B.B. 1998. Illustrated genera of imperfect fungi. 4 ed. APS Press, Minnesota.

Barron, G.L. 1968. The genera of Hyphomycetes from soil. The Williams \& Wilkins Company, Baltimore.

Booth, C. 1971. The genus Fusarium. The Lavenham Press, Surrey.

Cavalcanti, M.S. 2001. Fungos isolados da água e do solo das margens dos açudes do Prata e do Meio, na Reserva Florestal de Dois Irmãos, Recife-PE. Tese de doutorado, Universidade de São Paulo, São Paulo.

Ceballos, B.S.O., Lima, E.O., König, A. \& Martins, M.T. 1995. Spatial and temporal distribution of fecal coliforms, coliphages, moulds and yeasts in freshwater at the semi-arid tropic northeast region in Brazil (Paraiba State). Brazilian Journal of Microbiology 26: 90-100.

Christensen, M. 1989. A view of fungal ecology. Mycologia 81: 1-19.

CONAMA 2005. Classificação de águas doces, salinas e salobras. Resolução n 357, de 17 de março de 2005, Brasília.

Cooke, W.B. 1976. Fungi in sewage. In: E.B. Gareth Jones. Recent advances in aquatic mycology. Elek Science, London, pp. 389-434.

Dix, N.J. \& Webster, J. 1995. Fungal Ecology. Chapman \& Hall, Cambridge.

Domsch, K.H., Gams, W. \& Anderson, T.H.C. 1993. Compendium of soil fungi. Academic Press, San Francisco.

Ellis, M.B. 1971 . Dematiaceous Hyphomycetes. Commonwealth Mycological Institute, Kew.

Esteves, F.A. 1998. Fundamentos de limnologia. Interciência, Rio de Janeiro.

Kay, D. \& McDonald, A. 1980. Reduction of coliform bacteria in two upland reservoirs: the significance of distance decay relationships. Water Research 14: 305-318. 
Leslie, J.F. \& Summerell, B.A. 2006. The Fusarium laboratory manual. Blackwell Publishing, Iowa.

Martins, M.T., Gambale, W., Paula, C.R. \& Pelizzari, V.H. 1989. Utilização de bactérias e fungos como indicadores na avaliação de fatores fisiográficos que interferem nos processos de auto-depuração de um córrego sub-tropical. Brazilian Journal of Microbiology 20: 278-291.

Maki, J.S., Danos, S.C. \& Remsen, C.C. 1984. Quantitative changes in fungal colony-forming units in the surface microlayers of two freshwater ponds. Canadian Journal of Microbiology 30: 578-586.

Muller-Dombois, D. \& Ellenberg, H. 1974. Mathematical treatment of vegetation data. John Wiley, New York.

Noell, J. 1973. Slime-inhabiting geofungi in a polluted stream (winter/spring). Mycologia 65: 57-66.

Oliveira, J.C.G., Netto, A.M., De Angelis, J.A. \& Barbosa, M.A. 2001. Estação de flotação e remoção de flutuantes do Parque do Ibirapuera, São Paulo: a aplicação do processo de tratamento por flotação em fluxo para a recuperação de lagos urbanos. XXI Congresso Brasileiro de Engenharia Sanitária e Ambiental, João Pessoa.

Park, D. 1968. The ecology of terrestrial fungi. In: G.C. Ainsworth \& A.S. Sussman, The fungi: an advanced treatise. Academic Press, New York, pp. 5-37.

Park, D. 1972. On the ecology of heterotrophic microorganisms in freshwater. Transaction of the British Mycological Society 58: 291-299.

Pitt, J.I. 2000. A laboratory guide to common Penicillium species. Food Science Australia, North Ryde.
Prefeitura do Município de São Paulo. 2005. Resultados laboratoriais dos parâmetros de qualidade das águas do lago do Parque Ibirapuera. Período: setembro de 2004 a agosto de 2005. Secretaria Municipal do Verde e do Meio Ambiente, Departamento de Controle da Qualidade Ambiental, Divisão Técnica de Controle Ambiental, Seção Técnica de Apoio e Desenvolvimento Tecnológico, São Paulo.

Qureshi, A.A. \& Dutka, B.J.A. 1974. Preliminary study of the occurrence and distribution of geofungi in Lake Ontario near the Niagara River. Proceedings of the Seventeenth Conference on Great Lakes Research, Burlington. Part 11, pp. 653-662.

Schoenlein-Crusius, I.H. 1993. Sucessão fúngica em folhas de Alchornea triplinervia (Spreng.) M. Arg. em ambientes aquático e terrestre, na Mata Atlântica, Reserva Biológica do Alto da Serra de Paranapiacaba, Santo André, SP. Tese de Doutorado, Universidade Estadual Paulista, Rio Claro.

Sparrow Jr., F.K. 1968. Ecology of freshwater fungi. In: G.C,Ainsworth \& A.S, Sussman. The fungi: an advanced treatise. Academic Press, New York, v.3, pp. 41-83.

Souza, L.C., Iaria, S.T., Paim, G.V. \& Lopes, C.A.M. 1983. Bactérias coliformes totais e coliformes de origem fecal em águas usadas na dessendentação de animais. Revista de Saúde Pública 17: 112-22.

Tundisi, J.G. \& Tundisi, T.M. 2008. Limnologia. Oficina de Textos, São Paulo.

Warcup, J.H. 1950. The soil plate method for isolations of fungi from soil. Nature 166: 117-118.

Zak, J.C. \& Willig, M.R. 2004. Fungal biodiversity patterns. In: G.M. Muller \& M.S. Foster (eds.). Biodiversity of Fungi: Inventory and monitoring methods. Elsevier Academic Press, Burlington, pp. 9-76. 
